Check for updates

Cite this: RSC Adv., 2020, 10, 16125

\title{
The growth of methylammonium lead iodide perovskites by close space vapor transport
}

\author{
Alexander J. Harding, (D) ab Austin G. Kuba, ${ }^{\text {ab }}$ Brian E. McCandless, ${ }^{a}$ Ujjwal K. Das, ${ }^{a}$ \\ Kevin D. Dobson, (D) ${ }^{a}$ Babatunde A. Ogunnaike ${ }^{c}$ and William N. Shafarman (D)*ab
}

\begin{abstract}
Vapor deposition processes have shown promise for high-quality perovskite solar cells with potential pathways for scale-up to large area manufacturing. Here, we present a sequential close space vapor transport process to deposit $\mathrm{CH}_{3} \mathrm{NH}_{3} \mathrm{Pbl}_{3}$ (MAPI) perovskite thin films by depositing a layer of $\mathrm{Pbl}_{2}$ then reacting it with $\mathrm{CH}_{3} \mathrm{NH}_{3}$ ( $\left(\mathrm{MAl}\right.$ ) vapor. We find that, at $T=100{ }^{\circ} \mathrm{C}$ and pressure $=9$ torr, a $\sim 225 \mathrm{~nm}$-thick $\mathrm{Pbl}_{2}$ film requires $\geq 125$ minutes in MAI vapor to form a fully-reacted MAPI film. Raising the temperature to $160{ }^{\circ} \mathrm{C}$ increases the rate of reaction, such that MAPI forms within 15 minutes, but with reduced surface coverage. The reaction kinetics can be approximated as roughly first-order with respect to $\mathrm{Pbl}_{2}$, though there is evidence for a more complicated functional relation. Perovskite films reacted at $100{ }^{\circ} \mathrm{C}$ for 150 minutes were fabricated into solar cells with an SLG/ITO/CdS/MAPI/Spiro-OMeTAD/Au structure, and a device efficiency of $12.1 \%$ was achieved. These results validate the close space vapor transport process and serve as an advance toward scaled-up, vapor-phase perovskite manufacturing through continuous vapor transport deposition.
\end{abstract}

Received 20th February 2020

Accepted 7th April 2020

DOI: $10.1039 / \mathrm{dOra01640c}$

rsc.li/rsc-advances fostered the deployment of a commercial VTD process for largearea, uniform CdTe deposition by First Solar LLC. ${ }^{16}$

Despite this success, an all-vapor CSVT process for perovskite thin film deposition has not been investigated. Therefore, feasible processing temperatures and pressures have not been defined, and their effect on deposition rate, film quality, and device performance are unknown. There are only a few reports of methylammonium iodide $\left(\mathrm{CH}_{3} \mathrm{NH}_{3} \mathrm{I}, \mathrm{MAI}\right)$ reactions in a CSVT configuration with spin-coated $\mathrm{PbI}_{2}$ followed by annealing to drive a reaction between $\mathrm{PbI}_{2}$ and MAI vapor. ${ }^{17-19}$ However, these studies do not provide sufficient information to develop a VTD reactor for scaled-up perovskite manufacturing because they omit the vapor deposition of the $\mathrm{PbI}_{2}$ film.

The application of an all-vapor CSVT process to directly deposit methylammonium lead iodide $\left(\mathrm{CH}_{3} \mathrm{NH}_{3} \mathrm{PbI}_{3}, \mathrm{MAPI}\right)$ thin films must differ from CdTe deposition by CSVT, where the absorber sublimes from a single molecular source to form Cd and $\mathrm{Te}_{2}$ vapors that react at the substrate and form a solid film, ${ }^{\mathbf{1 6}}$ because the vapor pressures of the constituent compounds of MAPI perovskites $\left(\mathrm{PbI}_{2}\right.$ and $\left.\mathrm{MAI}\right)$ are too dissimilar to deposit stoichiometric films from a single source. $^{20,21}$ Therefore, a two-stage CSVT process has been developed to form the MAPI absorber layer by depositing a film of $\mathrm{PbI}_{2}$ and reacting it in MAI vapor as shown in Fig. 1. Here we report the deposition of $\mathrm{PbI}_{2}$ films via CSVT, their reaction with MAI vapor, a reaction kinetic model, an upper-threshold to reaction temperature, and functional devices achieving $12.1 \%$ efficiency.
${ }^{a}$ Institute of Energy Conversion, University of Delaware, Newark, Delaware, 19716, USA. E-mail:wns@udel.edu; Tel: +1-302-831-6200

${ }^{b}$ Materials Science and Engineering, University of Delaware, Newark, DE, 19716, USA ${ }^{c}$ Chemical and Biomolecular Engineering, University of Delaware, Newark, DE, 19716, USA 

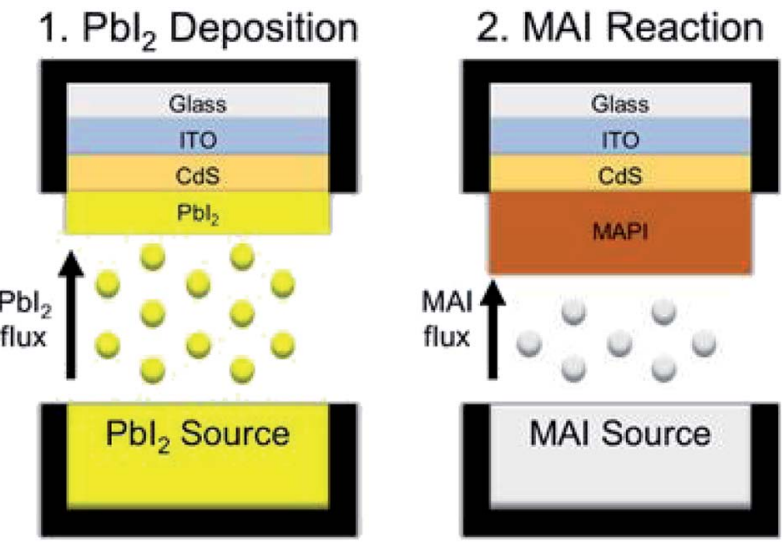

Fig. 1 A schematic of the two-stage CSVT process used to deposit MAPI thin films.

\section{Experimental approach}

\subsection{Substrate preparation}

Soda-lime glass (SLG) substrates were sequentially cleaned by sonication in LiquiNOX ${ }^{\circledR}$ and CitraNOX ${ }^{\circledR}$ soaps, followed by rinsing in DI water and drying at $180^{\circ} \mathrm{F}$ for 1 hour. After drying, a $300 \mathrm{~nm}$ layer of ITO was RF sputtered at room temperature onto the substrates through a shadow mask to define cell area.

\subsection{CdS deposition by chemical surface deposition}

CdS was chosen as the electron transport layer because its conduction band lies $0.3 \mathrm{eV}$ below the perovskite's conduction band and due to its good hole-blocking properties. ${ }^{22}$ CdS was deposited on the ITO-coated SLG substrates using chemical surface deposition (CSD). ${ }^{23}$ The SLG/ITO substrates were heated on a hot plate to $55{ }^{\circ} \mathrm{C}$ and a solution was prepared containing $2.2 \mathrm{~mL} 1.5 \mathrm{mM} \mathrm{CdSO}_{4}$ (99.996\%, Alfa Aesar), 2.2 mL 1.5 M

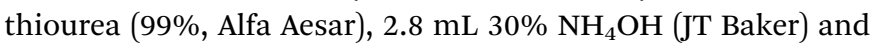
$15 \mathrm{~mL}$ DI water. Afterward, $1.5 \mathrm{~mL}$ of the solution was dispensed dropwise onto each of the hot substrates. After 5 minutes, the substrates were removed from heat, tipped of fluid, rinsed with flowing DI water, and dried with argon. The process was repeated to apply a second coat of CdS, yielding a uniform, $\approx 50 \mathrm{~nm}$ thick layer.

\subsection{CSVT reactor}

A photograph of the CSVT reactor developed for these experiments is shown in Fig. 2a. It consists of a planar sourcesubstrate geometry with the source positioned beneath the substrate. A motorized arm is used to position the apparatus in a $4.5 \mathrm{~cm}$ diameter quartz tube between two $1000 \mathrm{~W}$ lamps. These lamps independently heat two graphite susceptors, which are in direct contact with the source material and the substrates, as seen in Fig. 2b. Eurotherm 2404 controllers moderate the temperature of each susceptor using embedded thermocouples so that the heating lamps control the source and substrate temperatures between 25 and $500{ }^{\circ} \mathrm{C}$. A roughing pump, an argon carrier gas flowing at $10 \mathrm{sccm}$, two Baratron capacitance manometers, and a throttle valve maintain the
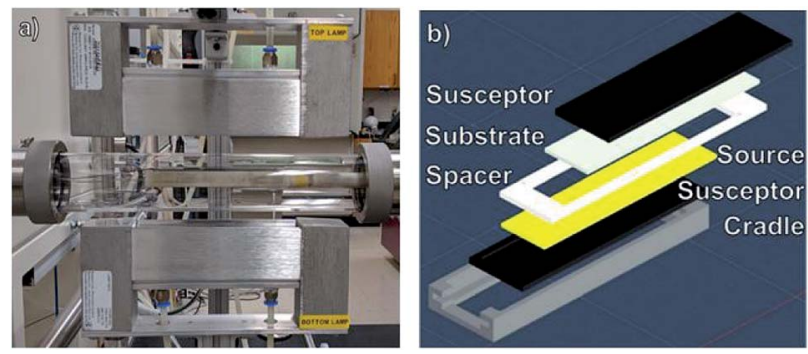

Fig. 2 (a) A photograph of the CSVT reactor. (b) An exploded view of the CSVT fixture and its components.

working pressure between 0.1 and 100 torr. The CSVT reactor is integrated with a multi-function glove box used to prepare, load, and unload the sources and substrates in a nitrogen atmosphere with $\mathrm{O}_{2}<0.1 \mathrm{ppm}$ and $\mathrm{H}_{2} \mathrm{O}<5 \mathrm{ppm}$. This allows the perovskite layer to be processed start-to-finish without exposure to ambient air.

Fig. $2 \mathrm{~b}$ shows an exploded schematic of the source and substrate holder. Insulating Macor ${ }^{\circledR}$ ceramic fittings hold the $10.8 \mathrm{~cm}$ long source and substrate susceptors in place and maintain a temperature gradient across a $2.2 \mathrm{~mm}$ gap defined by the spacer. This gradient promotes mass transport from the source to the substrates, resulting in deposition and film growth. The fittings also define the deposition area to be $\approx 20 \mathrm{~cm}^{2}$, which accommodates three $2.5 \mathrm{~cm} \times 2.5 \mathrm{~cm}$ substrates per run.

CSVT processing of MAPI is shown schematically in Fig. 1. CdS-coated SLG/ITO substrates are loaded face down into the CSVT chamber over a $\mathrm{PbI}_{2}$ source, and the system is pumped to a base pressure of $10^{-7}$ torr. The chamber is then backfilled with argon gas to a fixed working pressure, and the system is allowed to equilibrate for $5 \mathrm{~min}$. The lamps ramp the source and substrate susceptors to their temperature setpoints over $5 \mathrm{~min}$ at a fixed rate of $47{ }^{\circ} \mathrm{C} \mathrm{min}^{-1}$ for the source and $38{ }^{\circ} \mathrm{C} \min ^{-1}$ for the substrate. The source and substrate temperatures are then controlled to within $\pm 2{ }^{\circ} \mathrm{C}$ of their setpoints for a specified duration by independently modulating the top and bottom lamp power.

Following $\mathrm{PbI}_{2}$ deposition, the $\mathrm{PbI}_{2}$-coated substrates and the $\mathrm{PbI}_{2}$ source are unloaded from the CSVT reactor. Then a second source, filled with MAI powder, is loaded into the CSVT reactor with the $\mathrm{PbI}_{2}$-coated substrates. After pumping and backfilling, the source and the substrate susceptors are heated to their setpoints at a rate of $25{ }^{\circ} \mathrm{C} \mathrm{min}^{-1}$. MAI sublimes and saturates the headspace surrounding the $\mathrm{PbI}_{2}$ film, driving a solid-vapor reaction to form MAPI. Finished MAPI films are removed from the CSVT chamber into the glove box, washed with isopropanol (anhydrous 99.5\%, Sigma Aldrich) to remove residual MAI, blow-dried with argon, and annealed on a hotplate at $100{ }^{\circ} \mathrm{C}$ for 5 minutes.

\subsection{Rear contact preparation}

Spiro-OMeTAD (Spiro) (99\%, Sigma Aldrich) films were deposited using an established recipe from literature. ${ }^{24}$ The Spiro solution was stirred for 10 minutes and filtered through a $0.2 \mu \mathrm{m}$ PTFE filter to remove large particles prior to spin-coating. Spiro films 
were dynamically spin-coated by aliquoting $100 \mu \mathrm{L}$ of solution onto the substrate at $4000 \mathrm{rpm}$ for 10 seconds. The films were dried and stored in the dark in a dry air desiccator (relative humidity $<7.5 \%$ ) overnight prior to metallization.

Oxidized SLG/ITO/CdS/MAPI/Spiro samples were loaded into an electron beam evaporator and pumped to a base pressure of $10^{-6}$ torr. Gold films were deposited through a shadow mask at a rate of $6 \AA^{-1}$ to a final thickness of $100 \mathrm{~nm}$. The active area of the solar cells was defined by the overlap area between the gold and the ITO to be $0.24 \mathrm{~cm}^{2}$. The edges of the perovskite were removed with a razor blade to expose the ITO contacts, and silver paste was applied using Dotite ${ }^{\circledR}$ D-550 Silver Colloid (2SPI).

\subsection{Device measurement}

Current-voltage $(J-V)$ measurements were carried out using a setup maintained in the $\mathrm{N}_{2}$-filled glovebox. The intensity of a xenon arc lamp (Newport Oriel 67005 Housing; Newport Oriel 69907 Power Supply) was calibrated using a Si solar cell with a Schott KG-5 IR filter attached to the front. This limits the spectral sensitivity of the Si calibration cell to $800 \mathrm{~nm}$ and matches the spectral sensitivity of the calibration cell to test devices. The calibration value is based on quantum efficiency (QE) measurements and $J-V$ measurements on a class A Oriel solar simulator.

$J-V$ measurements were carried out in a 4-point probe configuration with scans between -0.4 and $1.2 \mathrm{~V}$ at a sweep rate of $200 \mathrm{~V} \mathrm{~s}^{-1}$ with 48 data points. Cells were scanned from reverse to forward bias then back. Afterward, cells were prebiased at $1.2 \mathrm{~V}$ for 60 seconds prior to measurement from $1.2 \mathrm{~V}$ forward bias to $-0.4 \mathrm{~V}$ reverse bias. The data exhibited minor oscillations due to capacitive coupling between the device and the source measure unit (SMU) or temporal variations in the light intensity, and, therefore, the data was smoothed using a 5-point adjacent average for clarity.

\subsection{Materials characterization}

Three scanning electron microscopes (SEM) were used to collect micrographs of various samples. An AMRAY 1810T Digital SEM was used at an accelerating voltage of $20 \mathrm{kV}$ to image MAPI samples reacted at $160{ }^{\circ} \mathrm{C}$ and perform energy dispersive X-ray spectroscopy (EDS). A Zeiss Auriga 60 High Resolution Field Emission SEM and a JSM-7400 High Resolution SEM were used at $3 \mathrm{kV}$ to image plan-view and cross-section imaging, respectively.

$\mathrm{X}$-ray fluorescence (XRF) measurements were obtained using an Oxford Instruments X-Strata 980 Coating Thickness Analyser to measure the thickness of the $\mathrm{PbI}_{2}$ films. Samples were measured over a $0.75^{\prime \prime} \times 0.875^{\prime \prime}$ area of the film using a $7 \times 8$ grid for a total of 56 equally-spaced data points that were used to determine the average thickness of each film.

The CSVT films were analyzed by X-ray diffraction (XRD) using a Philips/Norelco powder X-ray diffractometer using a CuK $\alpha$ X-ray source operating at $35 \mathrm{kV}$ and $20 \mathrm{~mA}$ in BraggBrentano parafocusing geometry. The scan settings were $0.05^{\circ}$ $2 \theta$ per step with a 4 second dwell time, over the $2 \theta$ range $10-30^{\circ}$ to cover the principal peaks of $\mathrm{PbI}_{2}$ and MAPI. The XRD data was smoothed and processed with the Rachinger correction to remove contributions from $\mathrm{CuK \alpha} \alpha_{2} \cdot{ }^{25}$ All peaks were indexed and assigned to phases based on $d$-spacing conformity with references for ITO (cubic $\mathrm{In}_{2} \mathrm{O}_{3}$, ICDD 00-006-0416), $\mathrm{PbI}_{2}$ (hexagonal, ICDD 01-080-1000), and MAPI (tetragonal, pattern generated using PowderCell 2.0 for space group $14 \mathrm{~cm}$ ).

The weight percent of $\mathrm{PbI}_{2}\left(w_{\mathrm{PbI}_{2}}\right)$ in each sample was estimated from the intensity ratio $(R)$ of the $\mathrm{PbI}_{2}$ (001) and MAPI (110) reflections, corrected for background, using standard quantitative powder diffraction analysis as shown in eqn (1). ${ }^{26}$ The detection limit of $\approx 0.1 \%$ is governed by the signal-to-noise of the data, which is governed by the scattering power of each phase, the instrumental noise, and the scan conditions.

$$
w_{\mathrm{PbI}_{2}}=100 \% \times\left(1-\frac{1}{1+0.08 R}\right)
$$

\section{Results}

\subsection{Deposition of $\mathrm{PbI}_{2}$ thin films}

Previous research indicates that for single-junction, perovskite solar cells, the optimal thickness of the MAPI absorber layer is
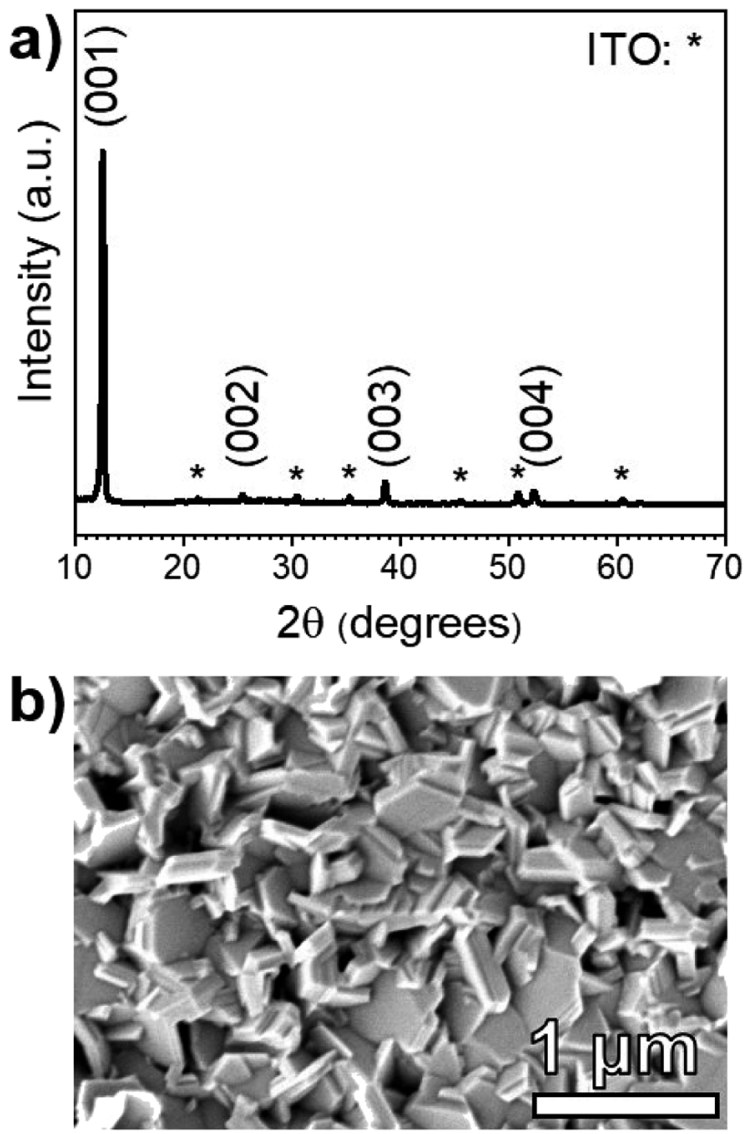

Fig. 3 (a) XRD pattern of $a \approx 225 \mathrm{~nm}$ thick $\mathrm{Pbl}_{2}$ film deposited on an $\mathrm{SLG} / \mathrm{ITO} / \mathrm{CdS}$ substrate at $T_{\text {source }}=260^{\circ} \mathrm{C}, T_{\text {sub }}=215^{\circ} \mathrm{C}, P=1$ torr, and $t=20 \mathrm{~min}$. The principal $\mathrm{Pbl}_{2}$ planes are labeled at their respective diffraction peaks, and the ITO peaks are marked with an asterisk. (b) A plan-view SEM micrograph of the $\mathrm{Pbl}_{2}$ film. 
$\approx 400 \mathrm{~nm},{ }^{27}$ which requires the $\mathrm{PbI}_{2}$ precursor film to be $\approx 200 \mathrm{~nm}$ thick. ${ }^{28} \mathrm{PbI}_{2}$ was deposited using a source temperature $\left(T_{\text {source }}\right)=260{ }^{\circ} \mathrm{C}$, and a substrate temperature $\left(T_{\text {sub }}\right)=$ $215{ }^{\circ} \mathrm{C}$, according to a Clausius-Clapeyron fit of its vapor pressure $\left(P_{\mathrm{PbI}_{2}}^{\mathrm{vap}}\right),{ }^{20}$ to produce a vapor pressure difference of two orders of magnitude between the source $\left(P_{\text {source }}^{\text {vap }}\right)=2 \times 10^{-6} \pm 8$ $\times 10^{-7}$ torr and the substrate $\left(P_{\text {sub }}^{\mathrm{vap}}\right)=6 \times 10^{-8} \pm 3 \times 10^{-8}$ torr. Depositions were carried out at a pressure $(P)=1$ torr and the deposition time $(t)$ was varied to achieve a desired film thickness. A $20 \mathrm{~min}$ deposition $(t=20 \mathrm{~min}$ ) produced films with an average thickness of $225 \pm 7 \mathrm{~nm}$, measured by XRF.

The XRD pattern of a $\mathrm{PbI}_{2}$ film on an SLG/ITO/CdS substrate shown in Fig. 3a is fully indexed using hexagonal $\mathrm{PbI}_{2}$ and cubic $\mathrm{In}_{2} \mathrm{O}_{3}$ standards. Notably, CdS diffraction peaks are not observed due its low thickness $(\approx 50 \mathrm{~nm})$ and poor crystallinity. The $\mathrm{PbI}_{2} \mathrm{XRD}$ pattern shows the strongest diffraction peak at $2 \theta$ $=12.60^{\circ}$, which corresponds to the $(001)$ basal plane of hexagonal $\mathrm{PbI}_{2}$. In a random pattern of $\mathrm{PbI}_{2}$ powder, the brightest peak occurs at $25.90^{\circ}$ and corresponds to the (011) plane. This suggests that the $\mathrm{PbI}_{2}$ films deposited on CdS orient around the basal plane during the deposition process.

Fig. $3 \mathrm{~b}$ shows a plan-view SEM micrograph of the same $\mathrm{PbI}_{2}$ film. The morphology consists of hexagonal platelets that are consistent with the quasi-two-dimensional, $2 \mathrm{H}$ polytype of the $\mathrm{PbI}_{2}$ hexagonal crystal structure. ${ }^{29}$ While the film appears to have a rough texture, the $\mathrm{PbI}_{2}$ platelets seem to fully coat the CdS substrate with no visible pinholes.

\subsection{Reaction of $\mathrm{PbI}_{2}$ in MAI vapor}

MAI reactions of $\mathrm{PbI}_{2}$ films were carried out isothermally at $T_{\text {source }}=T_{\text {sub }}=100{ }^{\circ} \mathrm{C}$. The amount of MAI participating in the reaction is estimated from a Clausius-Clapeyron fit of the vapor pressure,$^{21}$ which gives $P_{\text {MAI }}^{\mathrm{vap}}=50 \pm 20 \mathrm{mTorr}$ at $T=100{ }^{\circ} \mathrm{C}$. The system pressure was maintained at a constant $P=9$ torr using an argon ambient, which diluted the concentration of MAI vapor.

A series of reactions were carried out from 25-150 $\mathrm{min}$ in 25 min increments. Fig. 4a shows the XRD patterns of the reacted films at each point in time. The conversion of $\mathrm{PbI}_{2}$ to MAPI is confirmed by the disappearance of the $\mathrm{PbI}_{2}$ (001) diffraction peak at $12.60^{\circ}$ and the appearance of the MAPI (110) and (220) peaks at $14.05^{\circ}$ and $28.40^{\circ}$ respectively. The $\mathrm{PbI}_{2}(001)$ intensity decreases and the MAPI (110) signal increases with increasing reaction time. After a $125 \mathrm{~min}$ reaction, the $\mathrm{PbI}_{2}$ signal is indistinguishable from the background. The morphology of the 150 min-reacted film from Fig. 4a is shown in Fig. 4 b. The film has a dense morphology that appears to be continuous across the CdS substrate without visible pinholes.

Quantitative X-ray diffraction intensity analysis ${ }^{26}$ was performed on the XRD patterns shown in Fig. 4a. A comparison of the $\mathrm{PbI}_{2}$ (001) and MAPI (110) peak intensities yielded the weight percent of $\mathrm{PbI}_{2}$ as a function of the reaction time, which was converted to moles $\left(N_{\mathrm{PbI}_{2}}\right)$ and plotted in Fig. 5. As $t$ increases, $N_{\mathrm{PbI}_{2}}$ decreases as it is converted to MAPI. This shows $>99 \%$ conversion from $\mathrm{PbI}_{2}$ to MAPI after $t=125 \mathrm{~min}$ at $T=$ $100{ }^{\circ} \mathrm{C}$ and $P=9$ torr.
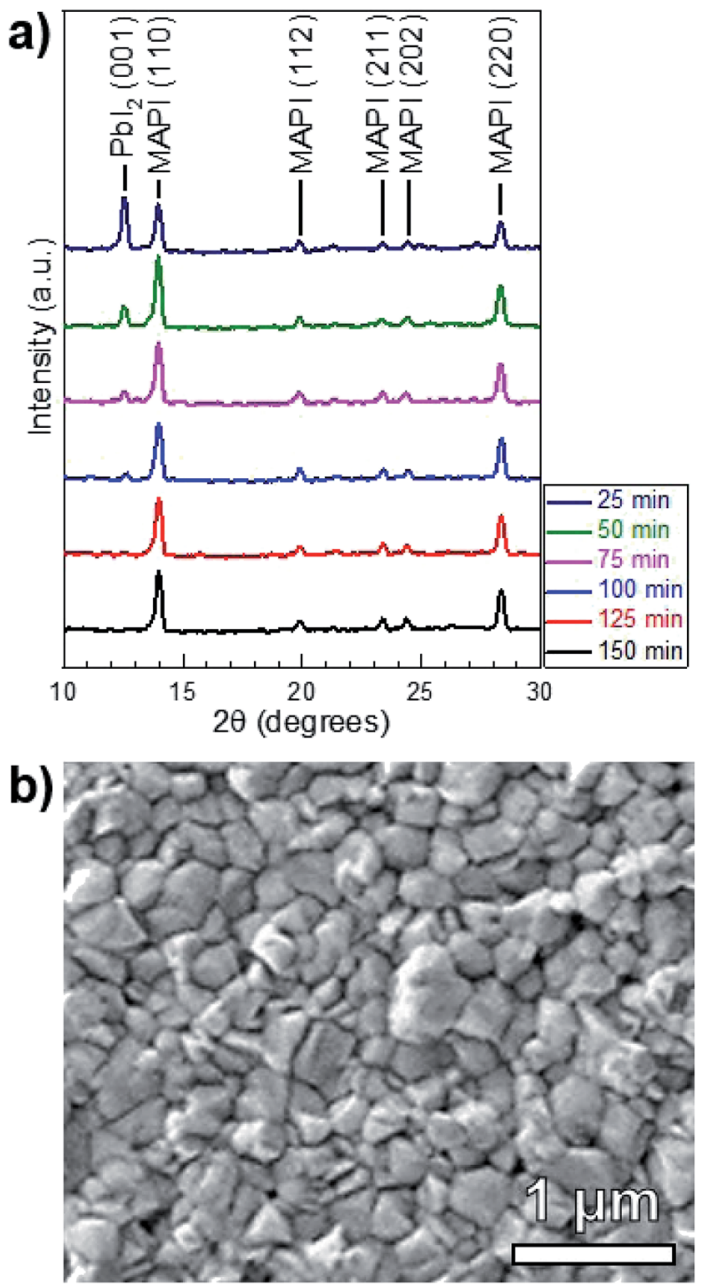

Fig. 4 (a) XRD patterns of MAPI films reacted isothermally in MAI at $T=$ $100{ }^{\circ} \mathrm{C}$ and $P=9$ torr for durations $t=25-150 \mathrm{~min}$. The principal $\mathrm{Pbl}_{2}$ and tetragonal MAPI peaks (space group $14 \mathrm{~cm}$ ) are labeled. (b) A planview SEM micrograph of the MAPI film reacted for $150 \mathrm{~min}$.

A linear fit of the data in Fig. 5 is used to approximate the first-order kinetic expression in eqn (2), where $k$ is the rate constant and $t$ is reaction time.

$$
\ln \left(\frac{N_{\mathrm{PbI}_{2}}}{N_{\mathrm{PbI}_{2, \mathrm{o}}}}\right)=-k t
$$

The associated $R^{2}$-value of 0.958 , and an adjusted- $R^{2}$-value of 0.950 , indicate that the first-order kinetic model is in reasonable agreement with the data; however, there is some visual evidence of curvature in the data, which may indicate a slightly more complicated functional relation. Consequently, we estimate the reaction rate constant, $k$, from the slope of the line as $k$ $=0.056 \pm 0.005 \mathrm{~min}^{-1}$. While this rate parameter is low, leading to reactions requiring $150 \mathrm{~min}$ to reach $>99 \%$ completion, it is likely to be a function of the reaction temperature and the concentration of MAI vapor, which are not explicitly included in the first-order model of eqn (2). This suggests that 


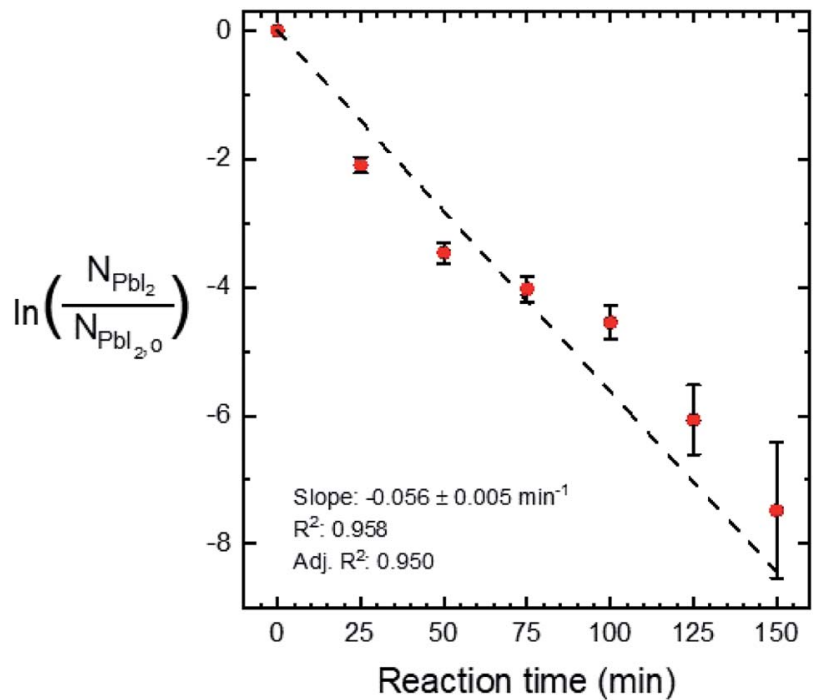

Fig. 5 The natural log of $N_{\mathrm{Pbl}_{2}}$ normalized to $N_{\mathrm{Pbl}_{2}, 0}$ versus reaction time. The error bars show $95 \%$ confidence intervals with increasing uncertainty with increasing reaction time, due to a decreasing signalto-noise ratio in the XRD measurement. A linear fit of the data is shown along with its slope, $R^{2}$, and adjusted $R^{2}$.

the reaction temperature and pressure can be tuned for faster reactions.

To investigate the effect of increased temperature and MAI concentration, another set of MAI reactions were carried out at $T=160{ }^{\circ} \mathrm{C}$ and $P=9$ torr, corresponding to an MAI vapor pressure of $P_{\mathrm{MAI}}^{\mathrm{vap}}=6 \pm 1$ torr $^{21}$-approximately two orders of magnitude higher than that of the $100{ }^{\circ} \mathrm{C}$ reactions. Fig. $6 \mathrm{a}$ shows the XRD patterns of films after 10 and 15 min reactions. There is a distinct $\mathrm{PbI}_{2}$ (001) peak at $12.60^{\circ}$ for the $10 \mathrm{~min}$ reaction, whereas the $\mathrm{PbI}_{2}$ peak is indistinguishable from the background after $15 \mathrm{~min}$. According to our quantitative analysis, this indicates $>99 \%$ conversion from $\mathrm{PbI}_{2}$ to MAPI. This reaction at $T=160{ }^{\circ} \mathrm{C}$ is an order of magnitude faster than the reaction at $T=100{ }^{\circ} \mathrm{C}$-indicating the rate of reaction is, in fact, a function of temperature. It is worth noting that the MAPI (112), (211), and (202) peaks are present in both the 10 and 15 min reactions.

Fig. $6 \mathrm{~b}$ shows that the resulting MAPI films have a discontinuous morphology of large agglomerates on the substrate surface. EDS was used to characterize the films and confirmed that the light gray agglomerates were MAPI and the dark background was the SLG/ITO/CdS substrate. This agglomeration may be caused by de-wetting from the substrate surface during the reaction process-possibly due to high interfacial surface energy between the substrate and the perovskite. Alternatively, it may be due to Ostwald ripening where small, thermodynamically unstable particles are incorporated into larger, more stables particles to minimize interfacial surface energy. ${ }^{30}$ Both phenomena typically occur at elevated temperatures due to increased adatom mobility, ${ }^{31}$ and suggest that the $160{ }^{\circ} \mathrm{C}$ reaction temperature is too high for MAPI processing on CdS at $P=9$ torr.
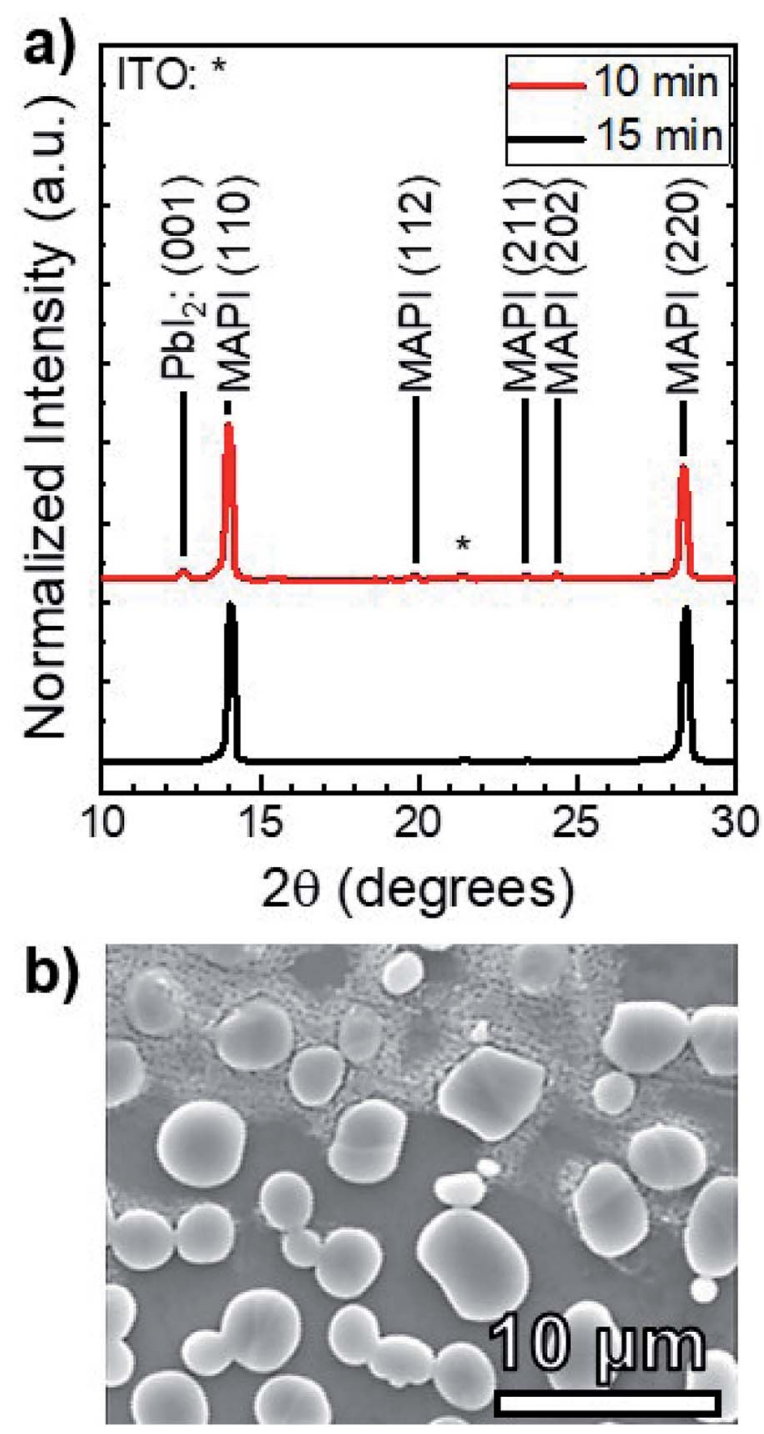

Fig. 6 (a) XRD patterns of MAPI films reacted isothermally at $T=$ $160^{\circ} \mathrm{C}$ and $P=9$ torr with durations of $t=10 \mathrm{~min}$ and $t=15 \mathrm{~min}$. The $\mathrm{Pbl}_{2}$ (001) peak and the tetragonal MAPI peaks are labeled. (b) A planview SEM micrograph of the 15 min-reacted MAPI film.

\subsection{Characterization of solar cells}

Fully-reacted MAPI films from $150 \mathrm{~min}$ reactions at $100{ }^{\circ} \mathrm{C}$ were integrated into functional solar cells with an SLG/ITO/CdS/ MAPI/Spiro/Au structure as shown in the cross-sectional SEM image of Fig. 7. The MAPI and Spiro layers appear to form pinhole-free films with only small thickness variations due to the intrinsic roughness of the MAPI layer. The MAPI grains appear to be dense and columnar with a grain width of $\approx 150$ $200 \mathrm{~nm}$. Furthermore, the reaction appears to have doubled the thickness of the original $\mathrm{PbI}_{2}$ film from $\approx 225 \mathrm{~nm}$ of $\mathrm{PbI}_{2}$ to $\approx 450 \mathrm{~nm}$ of MAPI.

A total of 50 solar cells were fabricated with identical $\mathrm{PbI}_{2}$ deposition, MAI reaction, and device processing conditions. A champion cell performance of $12.1 \%$ efficiency was achieved on a reverse sweep with open-circuit voltage $\left(V_{\text {OC }}\right)=980 \mathrm{mV}$, shortcircuit current $\left(J_{\mathrm{SC}}\right)=21.9 \mathrm{~mA} \mathrm{~cm}^{-2}$, and fill factor $(\mathrm{FF})=56.6 \%$ 


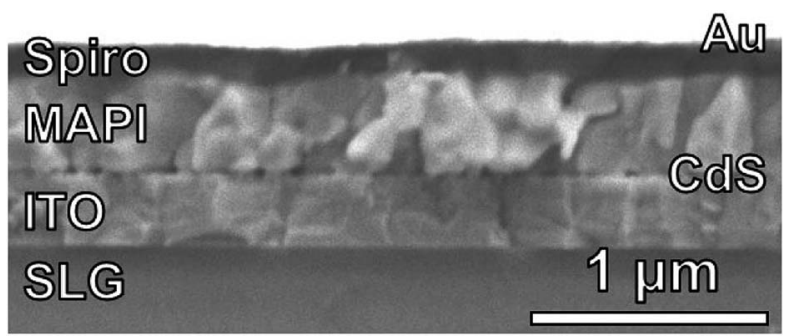

Fig. 7 A cross-sectional SEM image of a completed device with an SLG/ITO/CdS/MAPI/Spiro/Au stack.

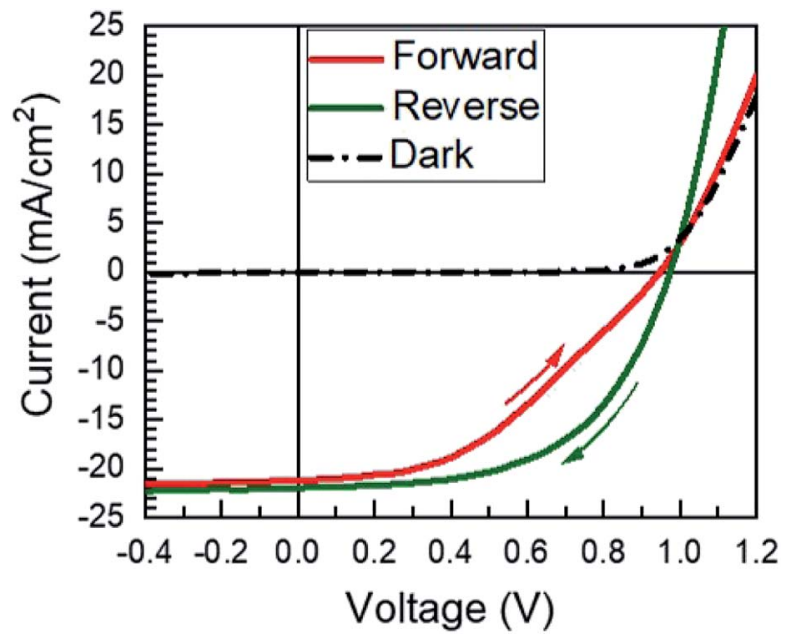

Fig. 8 The JV curve of the champion solar cell presented in this work. The arrows indicate the direction of the scan.

as shown in Fig. 8. However, this device exhibited hysteresis as evidenced by a lower efficiency of $8.4 \%$ during the forward sweep. This lower efficiency is due primarily to a loss in $\mathrm{FF}$ with $V_{\mathrm{OC}}=950 \mathrm{mV}, J_{\mathrm{SC}}=21.1 \mathrm{~mA} \mathrm{~cm}{ }^{-2}$, and $\mathrm{FF}=41.9 \%$. The higher performance in the reverse sweep is consistent with previous reports, which have attributed hysteretic effects to ion migration within the MAPI layer, where a positive voltage bias leads to better band alignment and improved carrier collection. ${ }^{32}$

The compiled cell parameters for all 50 devices are shown in Table 1. On average these cells exhibit a reasonable $V_{\mathrm{OC}}$ and $J_{\mathrm{SC}}$ of $968 \mathrm{mV}$ and $18.3 \mathrm{~mA} \mathrm{~cm}{ }^{-2}$ that can be incrementally improved upon to achieve high efficiency solar cells. However, there are substantial losses in FF that limit the efficiency. These losses can be attributed primarily to the CdS electron transport

Table 1 Device results and statistics for solar cells with a sample size of $n=50$. The error represents the $95 \%$ confidence interval around the average for each parameter

\begin{tabular}{lcl}
\hline Parameter & Average & Standard deviation \\
\hline$V_{\mathrm{OC}}(\mathrm{mV})$ & $968 \pm 6$ & 20 \\
$\left.J_{\mathrm{SC}}(\mathrm{mA} \mathrm{cm})^{-2}\right)$ & $18.3 \pm 0.6$ & 2.1 \\
FF $(\%)$ & $47.4 \pm 1.4$ & 5.0 \\
PCE $(\%)$ & $8.4 \pm 0.3$ & 1.1
\end{tabular}

layer because, in addition to parasitic absorption and a small conduction band spike, ${ }^{33}$ it has been reported that CdS can interact with excess MAI to form an interfacial Cd perovskite $\left(\mathrm{MA}_{2} \mathrm{CdI}_{4}\right){ }^{34}$ This would create a blocking barrier and reduce both the $J_{\mathrm{SC}}$ and the $\mathrm{FF}^{34}$ Therefore, it is likely that replacing CdS with a more appropriate electron transport layer, such as $\mathrm{SnO}_{2}$ or $\mathrm{TiO}_{2}$, could be used to improve the FF and the overall cell efficiency.

\section{Discussion}

This all-vapor CSVT process serves as an advance toward developing a commercial vapor deposition method for the production of perovskite thin films. However, there are several concepts that must be better understood before designing and implementing scaled VTD reactors. First, the perovskite field has moved away from the $\mathrm{CH}_{3} \mathrm{NH}_{3} \mathrm{PbI}_{3}$ composition toward alloys that include formamidinium, Cs, and $\mathrm{Br}$ because they have proven to be more stable and more efficient. ${ }^{3}$ It is apparent that a commercial perovskite production process will require the flexibility and methods to incorporate alloys into the material. Second, a quantitative mass transport model of the vapor deposition process is necessary to develop a scaled-up process. The composition of the alloyed perovskite film is essential to its performance and stability; therefore, a model is needed to guide experimentation toward a targeted composition. Finally, VTD of perovskites could be carried out either via a sequential process, as illustrated through CSVT, or via a simultaneous process. While the sequential process is limited by the rate of $\mathrm{PbI}_{2}$ conversion, a sequential process could circumvent this issue by co-depositing the perovskite's constituent materials through a low-vacuum and high-throughput process. Any effort to address one of these outstanding issues would be of great importance in developing perovskite vapor processing at the commercial scale.

\section{Conclusions}

This work establishes a sequential, all-vapor CSVT process to fabricate single-phase $\mathrm{CH}_{3} \mathrm{NH}_{3} \mathrm{PbI}_{3}$ perovskite thin films. Vapor-processed $\mathrm{PbI}_{2}$ films deposited on a $\mathrm{CdS}$ substrate possess a hexagonal, platelet-like morphology oriented about the (001) basal plane. Reacting these films at $100{ }^{\circ} \mathrm{C}$ and 9 torr produces continuous MAPI films, but this reaction temperature yields a slow reaction that requires at least $125 \mathrm{~min}$ to reach complete conversion. The change in $\mathrm{PbI}_{2}$ phase content versus time was used to quantify the rate of reaction, however further study is needed to develop a more accurate kinetic mechanism. Reacting the $\mathrm{PbI}_{2}$ films at $160{ }^{\circ} \mathrm{C}$ and 9 torr yields complete conversion to MAPI in $15 \mathrm{~min}$, but this elevated reaction temperature promotes de-wetting from the substrate which inhibits the formation of a continuous MAPI film. Devices fabricated from MAPI processed at $T=100{ }^{\circ} \mathrm{C}$ in the configuration SLG/ITO/CdS/MAPI/Spiro/Au achieved a champion cell efficiency of $12.1 \%$ with $V_{\mathrm{OC}}=980 \mathrm{mV}, J_{\mathrm{SC}}=21.9 \mathrm{~mA} \mathrm{~cm}^{-2}$, and $\mathrm{FF}=56.6 \%$. These results validate CSVT as a viable processing technique for perovskite solar applications and establish 
a foundation for further research into scaling perovskite production through VTD.

\section{Conflicts of interest}

There are no conflicts to declare.

\section{Acknowledgements}

This material is supported in part by the Engineering Research Center Program of the National Science Foundation and the Solar Energy Technology Office of the Department of Energy under NSF Cooperative Agreement No. EEC-1041895. The authors also wish to acknowledge Shannon Fields for constructing the CSVT reactor, Wayne Buchanan for ITO and Au depositions, and Chris Thompson for assistance with JV setup and testing.

\section{Notes and references}

1 J. A. Christians, P. Schulz, J. S. Tinkham, T. H. Schloemer, S. P. Harvey, B. J. Tremolet De Villers, A. Sellinger, J. J. Berry and J. M. Luther, Nat. Energy, 2018, 3, 68-74.

2 G. Grancini, C. Roldán-Carmona, I. Zimmermann, E. Mosconi, X. Lee, D. Martineau, S. Narbey, F. Oswald, F. De Angelis, M. Graetzel and M. K. Nazeeruddin, Nat. Commun., 2017, 8, 1-8.

3 M. Saliba, T. Matsui, J. Y. Seo, K. Domanski, J. P. CorreaBaena, M. K. Nazeeruddin, S. M. Zakeeruddin, W. Tress, A. Abate, A. Hagfeldt and M. Grätzel, Energy Environ. Sci., 2016, 9, 1989-1997.

4 D. Yang, R. Yang, K. Wang, C. Wu, X. Zhu, J. Feng, X. Ren, G. Fang, S. Priya and S. F. Liu, Nat. Commun., 2018, 9, 3239.

5 N. J. Jeon, H. Na, E. H. Jung, T. Y. Yang, Y. G. Lee, G. Kim,

H. W. Shin, S. Il Seok, J. Lee and J. Seo, Nat. Energy, 2018, 3, 682-689.

6 E. H. Jung, N. J. Jeon, E. Y. Park, C. S. Moon, T. J. Shin, T. Y. Yang, J. H. Noh and J. Seo, Nature, 2019, 567, 511-515.

7 S. Razza, F. Di Giacomo, F. Matteocci, L. Cinà, A. L. Palma, S. Casaluci, P. Cameron, A. D'Epifanio, S. Licoccia, A. Reale, T. M. Brown and A. Di Carlo, J. Power Sources, 2015, 277, 286-291.

8 S. G. Li, K. J. Jiang, M. J. Su, X. P. Cui, J. H. Huang, Q. Q. Zhang, X. Q. Zhou, L. M. Yang and Y. L. Song, J. Mater. Chem. A, 2015, 3, 9092-9097.

9 K. Hwang, Y. S. Jung, Y. J. Heo, F. H. Scholes, S. E. Watkins, J. Subbiah, D. J. Jones, D. Y. Kim and D. Vak, Adv. Mater., 2015, 27, 1241-1247.

10 B. Dou, J. B. Whitaker, K. Bruening, D. T. Moore, L. M. Wheeler, J. Ryter, N. J. Breslin, J. J. Berry, S. M. Garner, F. S. Barnes, S. E. Shaheen, C. J. Tassone, K. Zhu and M. F. Van Hest, ACS Energy Lett., 2018, 3, 25582565.

11 Y. Zhong, R. Munir, J. Li, M.-C. Tang, M. R. Niazi, K. Zhao and A. Amassian, ACS Energy Lett., 2018, 3, 1078-1085.
12 G. E. Eperon, S. D. Stranks, C. Menelaou, M. B. Johnston, L. M. Herz and H. J. Snaith, Energy Environ. Sci., 2014, 7, 982-988.

13 L. Gil-Escrig, C. Momblona, M. G. La-Placa, P. P. Boix, M. Sessolo and H. J. Bolink, Adv. Energy Mater., 2018, 8, 1-6.

14 M. R. Leyden, L. K. Ono, S. R. Raga, Y. Kato, S. Wang and Y. Qi, J. Mater. Chem. A, 2014, 2, 18742-18745.

15 C. Momblona, L. Gil-Escrig, E. Bandiello, E. M. Hutter, M. Sessolo, K. Lederer, J. Blochwitz-Nimoth and H. J. Bolink, Energy Environ. Sci., 2016, 9, 3456-3463.

16 B. E. McCandless and J. R. Sites, in Handbook of Photovoltaic Science and Engineering, ed. A. Luque and S. Hegedus, John Wiley \& Sons, Chichester, United Kingdom, 2nd edn, 2011, ch. 14, pp. 600-641.

17 G. Li, J. Y. L. Ho, M. Wong and H.-S. Kwok, Phys. Status Solidi $R R L, 2016,10,153-157$.

18 Q. Guo, C. Li, W. Qiao, S. Ma, F. Wang, B. Zhang, L. Hu, S. Dai and Z. Tan, Energy Environ. Sci., 2016, 9, 1486-1494.

19 E. Pérez-Gutiérrez, M. J. Percino, D. M. Montoya, D. SolisIbarra, M. Cerón and O. Barbosa-García, ACS Appl. Energy Mater., 2018, 3843-3849.

20 R. J. Konings, E. H. Cordfunke, J. E. Fearon and R. R. Van Der Laan, Thermochim. Acta, 1996, 273, 231-238.

21 A. Dualeh, P. Gao, S. I. Seok, M. K. Nazeeruddin and M. Grätzel, Chem. Mater., 2014, 26, 6160-6164.

22 G. Tong, Z. Song, C. Li, Y. Zhao, L. Yu, J. Xu, Y. Jiang, Y. Sheng and K. Chen, RSC Adv., 2017, 7, 19457-19463.

23 B. E. McCandless and W. N. Shafarman, Proceedings of the 3rd World Conference on Photovoltaic Energy Conversion, Osaka, 2003, pp. 562-565.

24 M. Saliba, J. P. Correa-Baena, C. M. Wolff, M. Stolterfoht, N. Phung, S. Albrecht, D. Neher and A. Abate, Chem. Mater., 2018, 30, 4193-4201.

25 W. A. Rachinger, J. Sci. Instrum., 1948, 25, 254-255.

26 H. Klug and L. Alexander, X-ray Diffraction Procedures For Polycrystalline and Amorphous Materials, John Wiley \& Sons, New York, 2nd edn, 1954.

27 Q. Lin, A. Armin, R. C. R. Nagiri, P. L. Burn and P. Meredith, Nat. Photonics, 2015, 9, 106-112.

28 D. Liu, M. K. Gangishetty and T. L. Kelly, J. Mater. Chem. A, 2014, 2, 19873-19881.

29 P. A. Beckmann, Cryst. Res. Technol., 2010, 45, 455-460.

30 M. Grundmann, The Physics of Semiconductors, Springer US, New York, 3rd edn, 2016.

31 D. L. Smith, Thin Film Deposition: Principles and Practice, McGraw-Hill, Inc., New York, 1995.

32 C. Eames, J. M. Frost, P. R. Barnes, B. C. O'Regan, A. Walsh and M. S. Islam, Nat. Commun., 2015, 6, 7494.

33 S. Bansal and P. Aryal, 2017 IEEE 44th Photovoltaic Specialist Conference, PVSC 2017, 2017, pp. 1-4.

34 W. A. Dunlap-Shohl, R. Younts, B. Gautam, K. Gundogdu and D. B. Mitzi, J. Phys. Chem. C, 2016, 120, 16437-16445. 